\title{
Learning in 3-D multiuser virtual environments: Exploring the use of unique 3-D attributes for online problem-based learning
}

\author{
Nicholas Omale, Wei-Chen Hung, Lara Luetkehans and \\ Jessamine Cooke-Plagwitz
}

Nicholas Omale is a doctoral candidate in the Department of Educational Technology, Research $\mathcal{E}$ Assessment at Northern Illinois University. His research interests include online learning technologies, technology for foreign language learning, and games and simulations. Wei-Chen Hung is an associate professor in the Department of Educational Technology, Research $\mathcal{E}$ Assessment at Northern Illinois University. His research interests include problem-based learning, human computer interaction, and performance support systems. Lara Luetkehans is an associate professor in the Department of Educational Technology, Research $\mathcal{E}$ Assessment at Northern Illinois University. Her research interests are in the areas of computer mediated communication and collaboration, and technology focused school university partnerships. Jessamine Cooke-Plagwitz is an assistant professor in the Department of Foreign Languages and Literatures at Northern Illinois University where she teaches courses in the German language and in technology-enhanced instruction for language teachers. Her research interests include online L2 instruction, authentic assessment models, and technology-enhanced Constructivist learning models. Address for correspondence: Nicholas Omale, Department of Educational Technology, Research and Assessment, Northern Illinois University, DeKalb, IL 60115-2854, USA. Email: nomale@ gmail.com

\begin{abstract}
The purpose of this article is to present the results of a study conducted to investigate how the attributes of 3-D technology such as avatars, 3-D space, and comic style bubble dialogue boxes affect participants' social, cognitive, and teaching presences in a blended problem-based learning environment. The community of inquiry model was adopted to analyse and interpret data collected from transcripts and group interviews. The results indicated that although the attributes of 3-D technology promoted participants' social presence, this positive online social experience did not completely contribute to participants' cognitive presence due to inherent technology attributes. Additionally, critical technical and instructional features of the 3-D environment were required in order to further enhance teaching presence and overall learning experience.
\end{abstract}

Research into learning and teaching with Internet technology has been widely recognised and discussed in recent years. One exciting trend in this field is the development of 3-D multiuser virtual environments (3-D MUVEs) where emphasis is placed on promoting community participants' social presence and collaborative inquiry (Barab, Thomas, 
Dodge, Carteaux \& Hakan, 2005; Berge, 2008; Dalgarno, 2002; Jones, Morales \& Knezek, 2005; Nelson, 2007). These 3-D MUVEs can be defined as 'a networked desktop virtual reality in which users move and interact in simulated 3-D spaces' (Dickey, 2005, p. 439). 3-D MUVEs can serve to motivate learners to engage in a series of purposeful educational inquiries without losing interest or sidestepping intended learning goals. Some entertainment features such as 3-D role playing and animated interactive environments are modelled after popular commercial games where players are placed in realistically rendered yet fancifully animated scenes while participating in a series of challenges or puzzles. Combining these concepts of animated scenery and challenges, 3-D MUVEs add meaningful educational resources and curriculum goals to "provide highly collaborative, immersive environments that promote interactions among students and with the instructor' (Jones et al, 2005, p. 221). Some popular 3-D MUVEs being used specifically for educational purposes include Active Worlds, Second Life, Quest Atlantis and River City (Qian, 2008).

The 3-D MUVEs are emerging learning technologies that have evolved from roleplaying games, computer games, text-based multiuser virtual environments and desktop virtual reality (Alexander, 2001; Jones et al, 2005). The term 3-D MUVEs, is at times used interchangeably with other terms for such settings as virtual worlds, 3-D online learning environments, and multiuser virtual environments (MUVEs). Alexander (2001) reports that 3-D virtual worlds or 3-D MUVEs will likely become a popular medium for online learning, as they provide learners with 'a sense of belonging' (p. 32).

\section{Research on 3-D MUVEs in education}

Research on the educational use of 3-D MUVES is gradually growing. For instance, studies have identified the motivational and social aspects of 3-D MUVEs (Barab et al, 2005; Dickey, 2005; Lim, Nonis \& Hedberg, 2006; de Jong, van der Meijden \& von Berg, 2005). Overall findings of these inquiries report that learners feel motivated as a result of the graphical interface of 3-D MUVEs since they are visually appealing, animated, and interactive. For example, Lim et al found that students 'showed their fascination of the teleport machines that brought them from one world to the next with sound effects' (p. 223). This study also found that students felt empowered by the fact that they could customise their avatars.

Similarly, Dickey (2005) found that 'visual cues such as buildings representing applications afford distance learners an intuitive interface for course structure in addition to providing the necessary resources for learning' (p. 444). Such an appeal is also reported by de Jong et al (2005) who find that '3-D learning environments can support an effective, active, and more playful learning process’ (p. 33). Barab et al (2005) report that the 3-D MUVE, Quest Atlantis, supports learner-centred collaborative inquiry by providing opportunities for learners to engage in meaningful learning through interactive quests and social games that promote interaction and community building online. 
Research has also been conducted to investigate the effect of 3-D MUVEs on learning outcomes (Dalgarno, 2002; Lim et al, 2006). Overall findings from these studies indicate that 3-D MUVEs did not enhance student learning because students were distracted and got off-task during their online activity. For example, Dalgarno (2002) investigates the effectiveness of the use of a 3-D virtual laboratory for chemistry education in a distance learning environment. Based on a formative evaluation, Dalgarno finds that 'although not as effective as a tour of the real laboratory, the virtual laboratory is an effective tool for developing familiarity with the laboratory and its apparatus' (p. 13). By the same token, Lim et al, found that students were so preoccupied with exploring the 3-D space that they subsequently failed to concentrate on their assignment.

These studies examined 3-D MUVEs as learning environments by seeking to understand how they support motivation, facilitate learning and improve learning outcomes. Although findings on learning outcomes are somewhat inconclusive, it would be interesting to learn how specific attributes of 3-D MUVEs, such as avatars, bubble dialogue boxes and the 3-D space, affect learning.

\section{Attributes of 3-D MUVEs}

The unique design feature of the 3-D MUVE lies in its technical attributes such as animated avatars and 3-D space (Jones \& Bronack, 2007). Unlike online chats where interaction with others is limited to text, these attributes of the 3-D MUVE add a unique visual dimension that allows learners to communicate with each other through movement and gestures of avatars and contextualisation in 3-D space (eg, a simulated classroom space). These attributes, as Salomon (1994) suggested, can serve as means of reference to encompass both semantic and pragmatic meanings, which allow learners to mentally construct their own messages and share them with others. For example, a symbol system such as charts and diagrams may provide an opportunity for a learner to visualise the causal relationship of phenomena and perform a comparative analysis; whereas other symbol systems may not call for such skills.

In addition to the animated avatars and the 3-D space, another unique attribute of some 3-D MUVEs is the Bubble dialogue Box. The bubble dialogue box attribute in 3-D MUVEs is designed to look like comic strip conversations, presents a non-linear forum for online synchronous discussion, and may thus play an important role in setting the scene for thoughtful discussions by learners. The use of bubble dialogue attributes in learning environments has been documented by previous studies by the Language Development and Hypermedia Research Group (1992). In their study, a bubble dialogue-based interpersonal computer simulation was used to facilitate and assess collaboration among learners, this team of researchers found that bubble dialogue boxes can hold learners' attention as they interact with one another. Unlike this interpersonal computer simulation, the bubble dialogue box in 3-D MUVEs is simply used for representing learners' text messages and does not provide prompts and assessment during the discussion. 
These attributes warrant further study as they each may provide specific pedagogical implications which enable learners to share meaning and build knowledge within an online learning environment. In order for us to identify these specific implications, we adopted the community of inquiry model (Garrison \& Anderson, 2003; Garrison, Anderson \& Archer, 2000) as the methodological framework to help us explore how the attributes can contribute to (or inhibit) an online problem-based learning (PBL) environment. The community of inquiry model has previously been used to understand learning in 3-D MUVEs. McKerlich and Anderson (2007) conducted an exploratory study to observe the effectiveness of the community of inquiry's presence indicators in assessing learning in MUVEs and found that the model's indicators can be effectively used to assess learning in MUVEs.

\section{Instructional implications of community of inquiry and PBL in 3-D MUVE}

The community of inquiry framework is based on the premise that a community of learners is an essential, core element of an educational experience when higher-order learning is the desired learning outcome' (p. 22). This framework comprises cognitive presence, social presence and teaching presence, which all work together to provide a successful online learning experience. According to Garrison et al (2000) cognitive presence is defined as 'the extent to which the participants in any particular configuration of a community of inquiry are able to construct meaning through sustained communication' (p. 89). Within this framework, the cognitive element is concerned with advancing the concepts of reflection and critical thinking among online learners.

The second element, social presence, is defined as 'the ability of participants in a community of inquiry to project themselves socially and emotionally, as 'real' people (ie, their full personality), through the medium of communication being used' (Garrison et al, 2000, p. 94). Social presence within a community of inquiry plays an important role in supporting the cognitive goals of learning (Rourke, Anderson, Garrison \& Archer, 1999).

The third element, teaching presence, according to Garrison and Anderson (2003) is defined as "the design, facilitation and direction of cognitive and social processes for the purpose of realising personally meaningful and educationally worthwhile learning outcomes' (p. 29). Teaching presence in a community of inquiry according to Garrison and Anderson recognises the important roles that teachers play as facilitators of communication and higher-order learning within an online learning context.

Garrison and Anderson (2003) further suggest that PBL may be a part of assessment activities to be supported by the community of inquiry framework. However, for PBL activities to be successful in online learning, Garrison and Anderson state that since most PBL activities are structured to allow group investigating, the needs for supporting group synchronisation, document management, discussion, and task assignment must be supported' (p. 100). If these design concerns are taken into account, 3-D MUVEs may be a suitable platform for collaborative online PBL group activities. PBL, like the community of inquiry framework, may advance critical thinking among a community 
of learners as they work together to find a solution to a given problem. Hence, the community of inquiry model may be an ideal framework for helping us understand the interactions in an online PBL collaborative activity.

\section{Purpose of the study}

The purpose of this case study was to understand the use of 3-D attributes in a blended online PBL environment and how these attributes affect group interactions within the context of Garrison and Anderson's (2003) community of inquiry model. The research question was: how do 3-D attributes such as avatars, 3-D space, and bubble dialogue boxes affect participants' social, cognitive and teaching presences in a blended PBL environment?

The use of blended online PBL in the study was intended to enhance group social performance (developing team climate, trust building, etc) and competence to achieve learning goals in an online learning environment (Kreijns \& Kirschner, 2004; Stahl, 2006). It was also an attempt to minimise the potential distraction caused by the 3-D attributes that may inherently inhibit the occurrence of social and teaching presences. For example, if all group members know each other prior coming online, there is a reduction in the time spent getting acquainted with each other. This in turn may improve group cohesion and direct their effort towards working together on the assignment. This combination of online and face-to-face instruction has proved to be an effective pedagogical technique for improving active and self-directed learning (see Bonk \& Graham, 2006).

\section{Methods}

An exploratory case study methodology was chosen for this investigation. The use of the case study approach is appropriate in this instance because the present study used a small sample size to explore situations where there is no clear or single set of outcomes, and to identify problems of practice by providing a holistic account of the phenomenon under investigation (Yin, 2003). Moreover, the present study aims to examine the impact of 3-D MUVE attributes on collaboration and interaction for an online PBL activity, by focusing on how these attributes sustain collaboration and interaction. The case study method allows us to collect detailed data, which illustrate patterns of participants' perceptions and reactions towards the use of these unique attributes (Savenye \& Robinson, 2004). The 3-D MUVE used in this study was ActiveWorlds, an online virtual community where users can appear as 3-D-based avatars able to travel and interact with other avatars.

\section{Participants}

Participants in this study consisted of two groups totalling eight part-time graduate students in a three-credit hour introductory instructional technology course at a Midwestern university. Participants were all adult learners with an age range between 
30 and 50, and they included five men and three women. All knew each other but had not worked together as a group prior to the study.

\section{Research procedure}

During the first class week, all eight participants participated in a 30-minute training session conducted by the first author in order to familiarise them with PBL and ActiveWorlds. A tutorial to help the participants to use ActiveWorlds was also provided as a quick reference. After the training session, the instructor distributed the case to the participants. The instructor then explained the PBL process and the learning objectives. Participants were free to ask questions pertaining to the PBL activity and the expected learning outcome (ie, assignment requirements), but not pertaining to the case itself. The case problem concerned selecting appropriate learning theories and instructional strategies for a large-scale middle-school science education training programme. In this case problem, an experienced educational technologist was hired by a university professor who received a grant for the development of a training programme for in-service teachers. The educational technologist's task was to identify appropriate media, instructional strategies, and delivery mode for the project. Problems arose when the educational technologist's traditional instructional design background conflicted with his client's constructivist philosophy. The participants' task was to develop a wellbalanced action plan that would meet the needs of the programme.

During week 2, the instructor conducted the class meeting online in ActiveWorlds. While the participants were online, the instructor randomly divided them into two groups of four. Once formed, groups were assigned to different virtual meeting rooms to discuss the assigned case. Participants were asked to use ActiveWorlds over the next 2 weeks as often as they desired. During these two weeks, both the first author and instructor came online when the groups met. However, the first author and instructor only observed and facilitated the online meetings; they did not provide any comments or guidelines related to the case solutions.

\section{Data analysis}

The first and second authors collected the data through discussion transcript (for ActiveWorlds), and group interviews with the goal of understanding how participants' online interactions supported their PBL activity. Transcript analysis provided us with evidence of learning and interaction patterns that were occurring in ActiveWorlds during the PBL activity. To understand these patterns further, we used the results of the transcript analysis as a catalyst for the group interviews with the participants. Our goal was to gain feedback from participants about their own understandings of the patterns that emerged, and to help us to understand the context in which these patterns were emerging. Table 1 shows how we employed the elements and indicators of community of inquiry model (Garrison \& Anderson, 2003) to study the impacts of 3-D MUVE attributes in a blended PBL environment.

This data analysis table seeks to demonstrate how the element of social, cognitive, and teaching presences within the community of inquiry model may support findings 
Table 1: Elements and indictors of community inquiry to study the impacts of 3-D MUVEs (3-D multiuser virtual environments) attributes in a blended problem-based learning (PBL) environment

\begin{tabular}{|c|c|c|}
\hline $\begin{array}{l}\text { 3-D MUVEs } \\
\text { Attributes }\end{array}$ & $\begin{array}{c}\text { PBL stage } \\
\text { (Barrows, 1986) }\end{array}$ & $\begin{array}{c}\text { Elements and indicators of community Inquiry } \\
\text { occurred in the PBL stage (adopted from } \\
\text { Garrison \& Anderson, 2003) }\end{array}$ \\
\hline
\end{tabular}

Avatar, 3-D Group formation environment, and bubble dialogue
Problem identification and problem analysis

Performance presentation
How the attributes affect group members' beginning interaction with each other:

Social presence

- Affective expression (expression of emotions, use of humour, self disclosure)

- Vocatives, inclusive pronouns

- Phatics, salutations (communication that serves a purely social function)

How the attributes affect group members' interaction with the problem:

Social presence

- Open communication (expressing agreement, asking questions, quoting)

Cognitive presence

- Evocative/inductive (recognising problem, puzzlement)

- Inquisitive/divergent

- Tentative/convergent

Teaching presence

- Setting learning goals and establishing time parameters

- Facilitating group discourse

- Diagnosing misconceptions

- Summarising the discussion

How the attributes affect group members' development of action plan:

Social presence

- Affective expression (expression of emotions, use of humour, self-disclosure)

Cognitive presence

- Committed/deductive (apply, test, defend)

Teaching presence

- Assessing the efficacy of the process

- Responding to technical concerns

related to the PBL stages of group formation, problem identification, problem analysis and performance presentation. This relational building also helped us triangulate our findings though which more than one approach is employed in the investigation of a research question in order to enhance confidence of findings (Merriam, 1998).

\section{Findings}

The four online sessions generated 1848 lines of dialogues with a total of approximately 13800 words. Participants did not meet outside the 3-D MUVE to solve the 
Table 2: Time spent and lines and words of discussion generated in ActiveWorlds by the participant

\begin{tabular}{lcccc}
\hline & Time* & $\begin{array}{c}\text { Online duration } \\
\text { (hour:minute) }\end{array}$ & Lines & Words \\
\hline Group 1 $(n=4)$ & Week 2 & $1: 38$ & 538 & 3880 \\
Group 2 $(n=4)$ & Week 3 & $1: 24$ & 453 & 2844 \\
& Week 2 & $1: 47$ & 572 & 5123 \\
& Week 3 & $1: 09$ & 285 & 1984 \\
\hline
\end{tabular}

*Week 1 class met face-to-face and was used for ActiveWorlds training.

problem, although email communication was used to exchange work. Table 2 reports the time spent, lines and words of lines of discussion generated in ActiveWorlds by the participant. To best explore and understand participants' learning experience in 3-D MUVEs, a thematic analysis approach was used to analyse both transcript and interview data. Data were read and reread in their entirety several times prior to analysis (Taylor \& Bogdan, 1984). This allowed us to obtain a holistic picture of participants' collective experiences.

A content expert was also recruited to code a 1200-word section of the data to check for coding reliability using the nVivo's Coding Comparison function. The coding comparison resulted in a Cohen's Kappa of 0.67 indicating satisfactory agreement. The organised and coded data were further analysed for frequency of occurrence. These descriptive data were organised and coded by the authors into themes using the elements and indictors of community inquiry typified in Table 1 . Table 3 shows the result of the frequency analysis of the coded themes.

Based on the thematic analysis, three theme statements were formulated to comprehend participants' learning experience in 3-D MUVEs.

First, the 3-D MUVEs appeared to be fun and engaging, but it was relatively easy for participants to get off task

Because participants were able to see each other and move around in the 3-D MUVE, they were more likely to engage in a face-to-face style interaction during online discussion. Throughout the problem-solving process, the researchers observed that participants spent a great deal of time engaging in social presence $(f=214,68 \%)$ in the form of humour, emotion expression and self-disclosure (GA $+\operatorname{PS}(f)=98,31 \%$ ), pure social communication $(\mathrm{GP}(f)=56,18 \%)$, vocatives $(\mathrm{GV}(f)=32,10 \%)$ and agreement and complementing $(\mathrm{AS}(f)=28,9 \%)$. Findings from interviews also confirmed such experiences:

It was engaging because it was fun. It was entertaining to learn. [Participant 6]

I really liked it [ActiveWorlds] ... . I have never IM'ed [Instant Message] anybody. And so it was really fun for me to IM and see people at the same time. But the really nice thing about it is that I felt like I was heard. [Participant 3] 
Table 3: Frequencies of the coded themes

\begin{tabular}{|c|c|c|c|}
\hline $\begin{array}{l}\text { Problem-based L\earning } \\
(P B L) \text { stage }\end{array}$ & $\begin{array}{l}\text { Indicators of community Inquiry } \\
\text { occurred in the PBL stage }\end{array}$ & f & $\%$ \\
\hline \multirow[t]{4}{*}{ Group formation } & Social presence & & \\
\hline & - Affective expression [GA] & 72 & 23 \\
\hline & - Vocatives, inclusive pronouns [GV] & 32 & 10 \\
\hline & - Phatics, salutations [GP] & 56 & 18 \\
\hline \multirow{10}{*}{$\begin{array}{l}\text { Problem identification } \\
\text { and problem analysis }\end{array}$} & Social presence & & \\
\hline & $\begin{array}{l}\text { - Open communication [AS] } \\
\text { Cognitive presence }\end{array}$ & 28 & 9 \\
\hline & - Evocative/inductive [AC 1] & 6 & 2 \\
\hline & - Inquisitive/divergent [AC 2] & 32 & 10 \\
\hline & - Tentative/convergent [AC 3] & 25 & 8 \\
\hline & Teaching presence* & & \\
\hline & $\begin{array}{l}\text { - Setting learning goals and establishing time } \\
\text { parameters [PT 1] }\end{array}$ & 9 & 3 \\
\hline & - Facilitating group discourse [AT 2] & 4 & 1 \\
\hline & - Diagnosing misconceptions [AT 3] & 3 & 1 \\
\hline & - Summarising the discussion [AT 4] & 6 & 2 \\
\hline \multirow[t]{6}{*}{ Performance presentation } & Social presence & & \\
\hline & - Affective expression [PS] & 26 & 8 \\
\hline & Cognitive presence & & \\
\hline & $\begin{array}{l}\text { - Committed/deductive (apply, test, defend) [PC] } \\
\text { Teaching presence* }\end{array}$ & 7 & 2 \\
\hline & - Assessing the efficacy of the process [PT 1] & 2 & 1 \\
\hline & - Responding to technical concerns [PT 2] & 8 & 3 \\
\hline
\end{tabular}

*The teaching presence was analysed based on participants' online discussion sessions. The course instructor did not participate in these online sessions.

I think that it [ActiveWorlds] was easier to discuss things with my group and ... you have to kind of feel your way around first, and then when you are comfortable, then the conversation can open up. [Participant 6]

However, the usefulness of the 3-D MUVE's attributes did not completely contribute to participants' cognitive presence. When relating the frequency results between overall social presence and cognitive presence, we see that social presence accounted for $68 \%$ $(f=214)$ of the frequencies of the coded themes throughout the three PBL stages, and cognitive presence accounted for $22 \%(\mathrm{AC} 1+\mathrm{AC} 2+\mathrm{AC} 3+\mathrm{PC}(f)=70)$. With respect to learning outcomes, it seems that participants occupied a great deal of time in social interaction to build social presence, but were unable to fully transfer this rich group synchronisation to the cognitive goals of learning.

Second, the 3-D MUVE attributes helped negotiation, clarification, and brainstorming among participants, but had relatively less influence on the organisation and convergence of problem solutions, partially because of certain technical barriers associated with the 3-D MUVE

While data collected from transcripts and focus group discussions revealed that 3-D attributes, such as avatars, and 3-D space, support self-disclosure and open communi- 
cation, these attributes may lead participants off-task if not appropriately guided. Participants felt that the assigned problem helped keep the group focused on discussion and helped set up a goal for their online meetings. As Participants 1 and 2 commented:

We started our conversation on our own, the problem we were working on without a doubt, seemed to kind of break the ice, for getting the project going. [Participant 1]

We had a built-in engagement because we were there to solve the problem. It [the problem] definitely kept us engaged. [Participant 2]

Indeed, the problem served as the gatekeeper for their online meetings. Even though the discussions were sometimes sidetracked, participants were usually able to resume quickly. Furthermore, it appeared that participants were able to clarify the ideas being discussed whenever they attempted to brainstorm possible solutions to the problem of designing instruction that reflected the client's constructivist view of learning. This was evident when comparing participants' discussion transcripts on divergent and convergent ideas, which had a relatively similar frequency $(\operatorname{AC} 2(f)=32,10 \% \operatorname{AC} 3(f)=25$, $8 \%$ ). Here is an example from both groups' transcripts, which illustrates how they attempted to unite the ideas provided.

Participant 3: I think the objective that Cynthia [the university professor] has presented to Denny [the educational technologist] are the overall problem statement but these smaller problems are also part of his dilemma

Participant 3: so combining them seems appropriate

Participant 2: But I guess this all goes back to my first question, is our goal to create the instruction or is our goal to solve Denny's problem?

Participant 1: So our problem is that-Denny needs to deliver effective instruction based on Cynthia's objectives but he does not have the basic information he needs to begin design

Participant 4: OK folks-Denny has a time issue. He is also having problems communicating with his boss. Thirdly, he has issues with the constructivists approach

And here is an excerpt for group 2 questioning the cognitive apprenticeship design approach:

Participant 7: I think our instruction needs to focus on taking the instructors and moving them from apprentices to masters, Cynthia in this model is the lead master

Participant 7: the other 68 instructors also represent masters as well

Participant 8: we need to do this without her help

Participant 5: we have some of the information needed for traditional ID approach

Participant 7: example?

Participant 6: I agree I think you just have to make Cynthia happy with a structured solution

Participant 5: We have to work backwards- the teachers can be interviewed so we can determine the objectives 
Participant 8: She wants a design that will teach teacher an alternative approach to structured learning of science

Participant 7: I think that is a must

However, transcript data revealed that participants were unable to go beyond idea sharing and clarification in 3-D MUVEs. When relating to the frequency result, we see participants had relatively few discussions related to generating possible solutions and finalising their action plans $(\mathrm{PC}(f)=7,2 \%)$. Another issue that emerged in this study is the need to embed more sharing features in ActiveWorlds, such as an online whiteboard in the 3-D environment to allow participants to hold demonstrations during a conversation as indicated by the participants during the focus group interviews.

I would have loved to have some sort of file document [uploading file to ActiveWorlds] where I would have posted up my case maybe in a PDF format where I'd highlight it in the PDF format. [Participant 2]

At this point I wouldn't use it [ActiveWorlds] for a corporate environment because there isn't much sharing going on. If I need to do something like that, I would just email. [Participant 4]

Additional information regarding participants' overall learning outcomes was provided through comments made by the course instructor, who compared the outcome of problem solutions to a Blackboard-threaded discussion he had used in previous courses. The instructor commented that both systems 'generated different outcomes and both outcomes are welcome'. When the instructor used Blackboard in his previous classes, the outcomes were directed more toward content mastery, with students focused on finding 'information from the textbooks that could be used to solve the case'. On the other hand, the participants in ActiveWorlds were "more dynamic and their solutions tended to be more inspired by the case context'. The instructor attributed this observation to the environment which provided a 'more relaxing and not-so academic-like learning tool that allowed students to bring their own personal understanding and experience to the case'.

Third, the embedded bubble dialogue allowed participants to gain collective reflections by following the discussion in the same way one might in a non-linear comic book conversation

Unlike text-based chat in which all messages appear in a dialogue box, the bubble dialogue attribute in ActiveWorlds is attached to one's avatar, much like the comic book's dialogue box. Figure 1 shows the layout of bubble dialogue.

This feature allows participants to make visual and mental connections with their team members. The bubble dialogue allowed them to engage in thoughtful discussions. The following transcript, excerpted from the Figure 1 scene, illustrates how the bubble dialogue allows participants to monitor each others' comments as they progress through a sociable sequence, as opposed to simply following a discussion in a traditional linear text box such as the chat box or threaded discussion: 


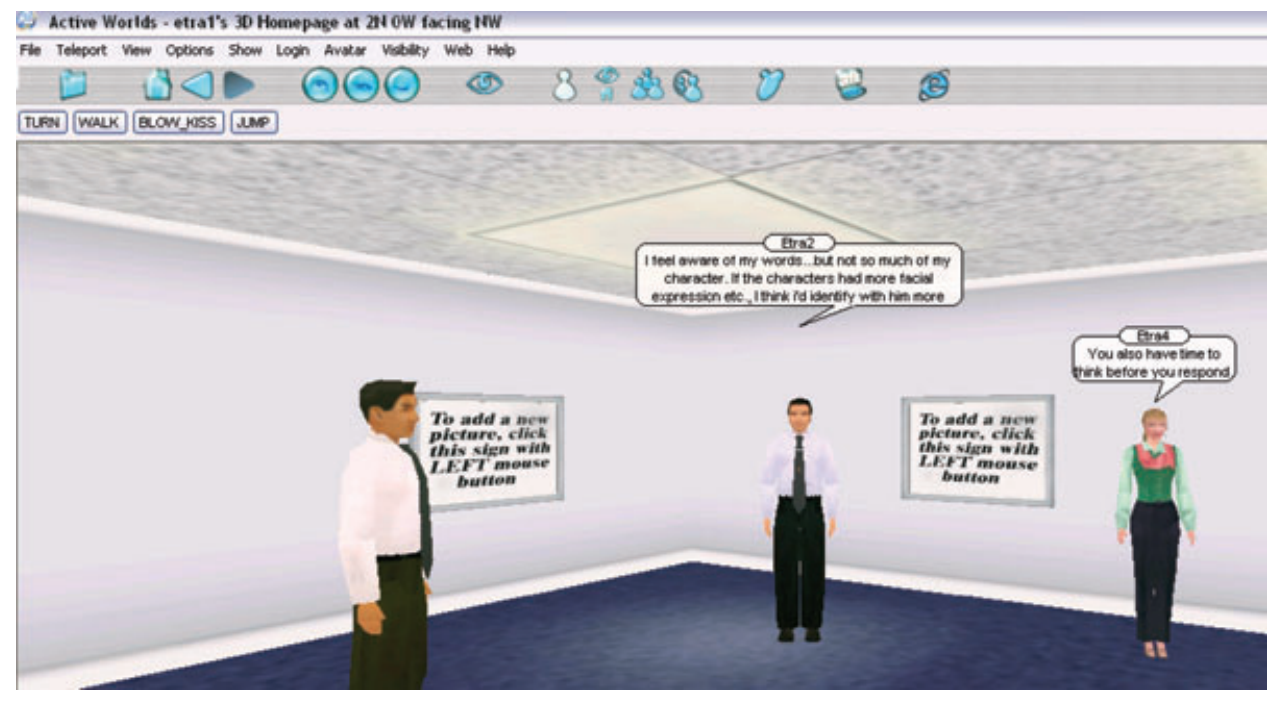

Figure 1: Layout of bubble dialogue

Participant 1: I think quite a bit. I am extremely conscious of what I am typing

Participant 2: I think you do think more about what you're going to say. You have the opportunity to edit yourself before you hit enter.

Participant 4: You also have time to think before you respond.

Participant 2: I feel aware of my words ...

Participant 4: I feel like I'm watching everyone else.

Participant 3: that would make you feel connected ...

Participants also confirmed their positive experiences with bubble dialogue boxes in the interviews:

I really like the bubbles. Makes it a lot more immediate and personal. [Participant 2]

... you are thinking of it as opposed to a face-to-face environment, it gives you more time to reflect ... I kept thinking of cartoons. [Participant 6]

Right, it's because you're writing it ..., you're using more senses I think, and kinesthetic by typing it and it is probably is going internally than just listening to somebody talk. [Participant 3]

It puts on a face even though it's an avatar face. You're not only looking at the username and this text, it gives you a feel of actually having a conversation. [Participant 4]

It almost personalises it. [Participant 7]

The bubble dialogue box in ActiveWorlds allows participants to reflect during the online discussion. This may be attributed to the fact that the bubble dialogue box is designed in a non-linear fashion and is thus intended to look like a comic book conversation. A similar finding was observed in a study by the Language Development and 
Hypermedia Research Group (1992). This research group observes that bubble dialogue "can produce conditions in the classroom where students are motivated to engage for surprisingly lengthy periods' (p. 44). The bubble dialogue feature in ActiveWorlds may therefore be a vital attribute for keeping learners on task during online collaborative learning by maintaining their motivation and engagement during online interaction.

\section{Conclusion and discussion}

The study findings suggest that the 3-D MUVE promoted social presence for the participants, but that this positive online social experience did not contribute greatly to participants' cognitive presence when relating to the frequency results (social presence $(f)=214,68 \%$ vs. cognitive presence $(f)=70,22 \%)$. Although the literature is inconclusive, this study supports the findings of Dalgarno (2002) and Lim et al (2006), showing that learning was not enhanced and that the technology became a distraction rather than an enabler. The features studied in this research (eg, avatar gestures, sounds) and animations (eg, avatar movement, bubble dialogue) in 3-D MUVEs, may overwhelm participants and send them off-task as they interact in the 3-D environment. While this finding does not corroborate with much of the literature related to the community of inquiry model (Garrison \& Anderson, 2003) it does not necessarily assert that 3-D MUVEs do not have the capacity to promote learning (ie, cognitive and teaching presences). Garrison et al (2000) suggest that 'sustained communication' is an integral element for supporting meaning construction and cognitive presence. In this study, the cognitive presence was lower than social presence but engagement in the environment was demonstrated. Perhaps over time, and with more exposure to the tools, students would have not relied on outside, and more familiar, tools (email) to share information and to organise their work. Faculty considering the use of MUVEs might consider building in 'play time' for the students to build familiarity and move beyond the novelty of the environment. Kanuka, Rourke and Laflamme (2007) found similar results of relatively low cognitive presence when comparing five different models of inquiry-based learning activities. They found that in order to achieve higher levels of cognitive presence the following attributes must also exist:

1. The activities are well structured.

2. Clearly defined roles and responsibilities for the students.

3. Students are provoked to explicitly confront others' opinions.

(Kanuka et al, 2007)

The instructional design for the online PBL activity used in this study included Kanuka et al's (2007) attributes 1 and 2, but the nature of the PBL activity did not require attribute 3. Familiarity with the environment and convergent/divergent activities might encourage more cognitive presence in future attempts at using 3-D MUVEs with inquiry-based learning activities.

Furthermore, part of the value of this study lies in the themes that emerged from explanations offered by participants as possible barriers to learning in the follow-up 
interviews. As suggested by participants, an ideal 3-D MUVE should include tools that allow participants to manage, organise and track their online discussions. This could be achieved by adapting a problem support repository; either embedded in or existing outside of the 3-D MUVEs to allow group members to access, track and present their problem analyses and ideas during their problem solving processes. Such support repositories may be as simple as an email attachment or as complicated as a databasedriven website where group members can organise and manage their PBL tasks. At present, work is being done to develop tools such as SLoodle, which combines the Moodle learning management system with the 3-D MUVE Second Life. Until such technology is widely available and has attained a level of user friendliness adequate to make the combination of 3-D MUVE and other online learning tools seamless and simple, faculty interested in using MUVEs in blended or online courses should consider increasing teacher presence through the use of facilitation techniques that provide prompts throughout the inquiry process as well as assessment and feedback (Garrison \& Cleveland-Innes, 2005).

In addition, it appears that the blended approach did not minimise the time participants spent in social conversion. Even though participants had known each other prior coming online, the excitement of 3-D MUVE attributes kept them preoccupied with exploring the features and functions embedded in the attributes. This suggests that participants perceived the 3-D MUVE as a tool for socialising and entertaining during their collaborative work. We think, therefore, that it is important when adopting 3-D MUVEs for collaboration in a blended learning approach to not only focus on helping learners fully comprehend the technology and its pedagogical purpose during the face-to-face instruction, but to take into account the entertaining nature of these attributes.

The scope of the theoretical and methodological framework used can be extended in order to make it more applicable for research in 3-D MUVEs. The community of inquiry model helped researchers understand cognitive, social, and teaching interactions in text-based online discussions. However, in relation to 3-D virtual environments, such as ActiveWorlds, the model may be inadequate in explaining data derived from online observations. Interaction in 3-D virtual environments typically includes avatar gestures, bubble chats, avatar movement, and sound within the 3-D space. Future research in 3-D MUVEs could explore alternative theoretical models such as social network analysis (de Laat, 2006), Communication analysis (Griffin, 1997) that might help to explain such interactions in online PBL.

Finally, the present study is a case study, not a designed experiment; therefore results may not be applicable to other type of learning environments or content areas. Data generated from the content analysis and interviews helped the researchers identify several key issues in using 3-D MUVEs for online PBL. However, the authors recommend further study that involves a comparative group using a different type of collaborative tool. 


\section{References}

Alexander, S. (2001). Learning in 3-D. OnlineLearning, July/August, 30-32.

Barab, S., Thomas, M., Dodge, T., Carteaux, R. \& Hakan, T. (2005). Making learning fun: quest Atlantis, a game without guns. Educational Technology Research and Development, 53, 1, 86-107.

Barrows, H. S. (1986). A taxonomy of problem-based learning methods. Medical Education, 20, $481-486$.

Berge, Z. L. (2008). Multi-user virtual environments for education and training? A critical review of Second Life. Educational Technology, 48, 3, 27-31.

Bonk, C. J. \& Graham, C. R. (Eds) (2006). Handbook of blended learning: global perspectives, local designs. San Francisco: Pfeiffer Publishing.

Dalgarno, B. (2002). The potential of 3D virtual learning environments: a constructivist analysis. Electronic Journal of Instructional Science and Technology, 5, 2, 1-19. Retrieved April 15, 2005 from http://www.usq.edu.au/electpub/e-jist/docs/Vol5_No2/Dalgarno\%20\%20Final.pdf

Dickey, M. D. (2005). Three-dimensional virtual worlds and distance learning: two case studies of Active Worlds as a medium for distance education. British Journal of Educational Technology, 36, 3, 439-451.

Garrison, D. R. \& Anderson, T. A. (2003). E-Learning in the 21st century: a framework for research and practice. New York: RoutledgeFalmer.

Garrison, D. R. \& Cleveland-Innes, M. (2005). Facilitating cognitive presence: interaction is not enough. The American Journal of Distance Education, 19, 3, 133-148.

Garrison, D. R., Anderson, T. \& Archer, W. (2000). Critical inquiry in a text-based environment: computer conferencing in higher education. The Internet and Higher Education, 2, 2-3, 87-107.

Griffin, E. (1997). A first look at communication theory. New York: The McGraw-Hill Companies.

Jones, J. G. \& Bronack, S. C. (2007). Rethinking cognition, representations, and processes in 3D online social learning environments. In D. Gibson, C. Aldrich, \& M. Prensky (Eds), Games and simulations in online learning: research and development frameworks (pp. 89-114). Hershey, PA: Information Science Publishing.

Jones, J. G., Morales, C. \& Knezek, G. A. (2005). 3-Dimensional online learning environments: examining attitudes toward information technology between students in internet-based 3-dimensional and face-to-face classroom instruction. Educational Media International, 42, 3, 219-236.

de Jong, F. P. C. M., van der Meijden, H. \& von Berg, J. (2005). 3D learning in the workplace and at school: playing, learning, or both? Educational Technology, 45, 5, 30-34.

Kanuka, H., Rourke, L. \& LaFlamme, E. (2007). The influence of instructional methods on the quality of online discussion. British Journal of Educational Technology, 38, 2, 260-271.

Kreijns, K. \& Kirschner, P. A. (2004). Designing sociable CSCL environments. In J.-W. Strijbos, P. A. Kirschner, \& R. L. Martens (Eds), What we know about CSCL: and implementing it in higher education (pp. 221-243). Norwell, MA: Kluwer Academic.

de Laat, M. (2006). Networked learning. Apeldoorn, the Netherlands: Politie Academy.

Language Development and Hypermedia Research Group (1992). Bubble dialogue: a new tool for instruction and assessment. Educational Technology Research and Development, 40, 2, 59-67.

Lim, C. P., Nonis, D. \& Hedberg, J. (2006). Gaming in a 3D multiuser virtual environment: engaging students in science lessons. British Journal of Educational Technology, 37, 2, 211-231.

Mc Kerlich, R. \& Anderson, T. (2007). Community of inquiry and learning in immersive virtual environments. Journal of Asynchronous Learning Networks, 11, 4, 35-52.

Merriam, S. B. (1998). Case study research in education—a qualitative approach. San Francisco, CA: Jossey-Bass.

Nelson, B. C. (2007). Exploring the use of individualized, reflective guidance in an educational multi-user virtual environment. Journal of Science Education and Technology, 16, 1, 83-97.

Qian, Y. (2008). Learning in 3-D virtual worlds: rethinking media literacy. Educational Technology, $48,2,38-41$. 
Rourke, L., Anderson, T., Garrison, D. R. \& Archer, W. (1999). Assessing social presence in asynchronous text-based computer conferencing. Journal of Distance Education, 14, 2, 50-71. Salomon, G. (1994). Interaction of media, cognition, and learning (2nd ed.). Erlbaum, NJ: Hillsdale. Savenye, W. C. \& Robinson, R. S. (2004). Qualitative research issues and methods: an Introduction for educational technologists. In D. H. Jonassen (Ed.), Handbook of research in educational communications and technology (2nd ed., pp. 1045-1071). Mahwah, NJ: Lawrence Erlbaum Associates, Publishers.

Stahl, G. (2006). Group cognition: computer support for building collaborative knowledge. Cambridge, MA: MIT.

Taylor, S. J. \& Bogdan, R. (1984). Introduction to qualitative research methods: the search for meanings. New York: John Wiley \& Sons.

Yin, R. K. (2003). Case study research: design and methods (2nd ed.). Thousand Oaks, CA: Sage Publications. 
Copyright of British Journal of Educational Technology is the property of Blackwell Publishing Limited and its content may not be copied or emailed to multiple sites or posted to a listserv without the copyright holder's express written permission. However, users may print, download, or email articles for individual use. 